\title{
Correspondence
}

\section{Secondary Lymphatic Insufficiency in Chronic Varicose Veins}

Antonio $\mathrm{M}$

antonio.manenti@unimore.it

\section{Alberto Farinett}

Gianrocco

Department of Surgery, University of Modena, Polyclinic Hospital, Modena, Italy

\section{Annavittoria Mattioli}

Department of Cardiology, University of Modena, Polyclinic Hospital, Modena, Italy

To the Editor,

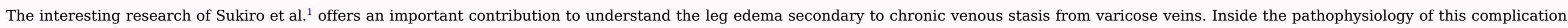

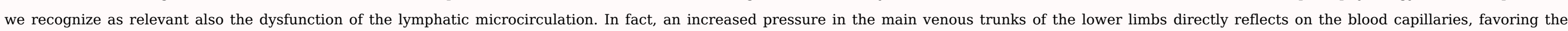

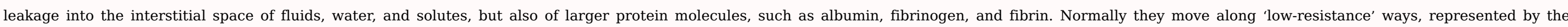

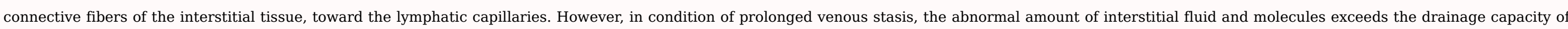

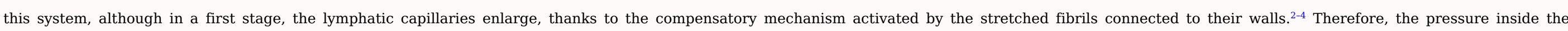

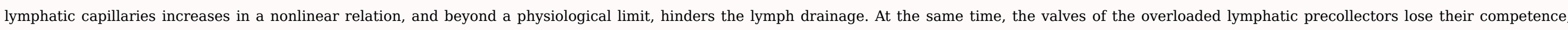

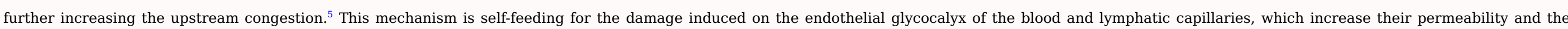

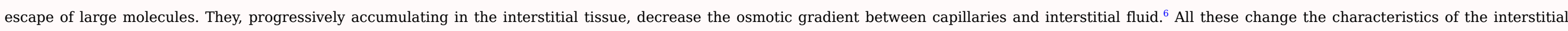

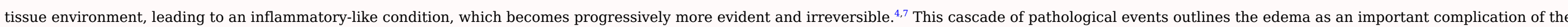

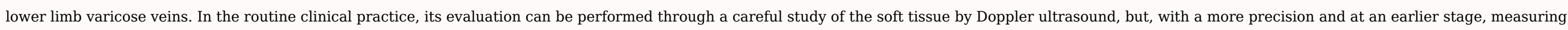
the extracellular fluid resistance and content through a bioimpedance analysis. ${ }^{1,7}$

\section{References}

1. K. Suchiro, N. Morikage, T. Harada, et al., Extracellular fluid content in the legs of patients with chronic venous disease, Ann Vasc Surg 2020, https://doi.org/10.1016/j.avsg.2020.07.046.

2. J.W. Breslin, Y. Yang, J.P. Scallan, et al., Lymphatic vessel network structure and physiology, Compr Physiol 9, 2019, 207-299.

3. D. Negrini and A. Moriondo, Lymphatic anatomy and biomechanics, J Physiol 589, 2011, 2927-2934.

4. H. Wiig and M.A. Swartz, Interstitial fluid and lymph formation and transport: physiological regulation and roles in inflammation and cancer, Physiol Rev 92, 2012, 1005-1060.

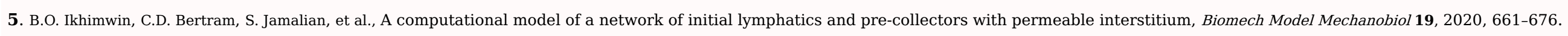

6. O. Yilmaz, B. Afsar, A. Ortiz, et al., The role of endothelial glycocalyx in health an disease, Clin Kidney J 12, 2019, 611-619.

7. A. Caggiati, Ultrasonography of skin changes in legs with chronic venous disease, EurJ Vasc Endovasc Surg 52, 2016, 534-542.

\section{Queries and Answers}

Query: If there are any drug dosages in your article, please verify them and indicate that you have done so by initialing this query 
Answer: No drug dosage in this article.

Query: Please update page range and volume number for the ref. [1].

Answer: Reference [1] concerns a paper still 'online ahead of print'.

Query: Refs. [4] and [7] were identical, the latter has been removed from the reference list and subsequent references have been renumbered.

Answer: I agree and thank you.

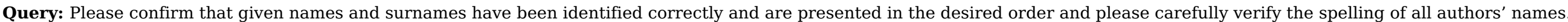
Answer: Yes 